Article

\title{
Direct Drive Applications: Possible Replacement of Rare-Earth Permanent Magnet Motors
}

\author{
Chaelim Jeong ${ }^{1, *(\mathbb{D})}$ Luca Cinti $^{2}$ (1) and Nicola Bianchi ${ }^{2}$ \\ 1 Department of Electrical Engineering, Tongmyong University, Busan 48520, Korea \\ 2 Department of Industrial Engineering, University of Padova, 35122 Padova, Italy; \\ luca.cinti@studenti.unipd.it (L.C.); nicola.bianchi@unipd.it (N.B.) \\ * Correspondence: cofla827@gmail.com
}

Citation: Jeong, C.; Cinti, L.; Bianchi, N. Direct Drive Applications:

Possible Replacement of Rare-Earth Permanent Magnet Motors. Energies 2021, 14, 8058. https://doi.org/ $10.3390 /$ en14238058

Academic Editors: Federico Barrero,

Nicola Bianchi and Ludovico Ortombina

Received: 7 November 2021

Accepted: 29 November 2021

Published: 2 December 2021

Publisher's Note: MDPI stays neutral with regard to jurisdictional claims in published maps and institutional affiliations.

Copyright: (c) 2021 by the authors. Licensee MDPI, Basel, Switzerland. This article is an open access article distributed under the terms and conditions of the Creative Commons Attribution (CC BY) license (https:// creativecommons.org/licenses/by/ $4.0 /)$.

\begin{abstract}
This paper deals with the possibility to replace rare-earth permanent magnet (PM) motors in direct drive applications. According to previous researches, there are alternatives such as surfacemounted PM motors and spoke-type motors adopting Ferrite PMs, synchronous reluctance motors, with or without the assistance of low-energy PMs. Few studies have been carried out to compare all models at once, thus it is hard to choose which type motor is to be preferred as a valid alternative of rare-earth PM motors in direct drive applications. In this paper, the representative candidates listed above are analyzed and the results are compared with that of a rare-earth PM motor, which is considered as a reference motor. Additionally, the demagnetization phenomenon of the motors with Ferrite PMs is deeply analyzed because this kind of PM may be easily demagnetized by the stator flux. Finally, both strengths and weaknesses of each alternative motors are highlighted.
\end{abstract}

Keywords: alternative motor; demagnetization; direct drive; ferrite permanent magnet; neodymium permanent magnet; rare-earth; synchronous motors; torque motor

\section{Introduction}

Direct drive motors are spotlighted due to their advantages, among the others the higher efficiency and the lower cost of the system, because the electric motor is able to deliver directly the torque without mechanical transmission elements such as gearboxes, chains or belts [1-3]. Since permanent magnet (PM) motors exhibit high torque density and efficiency, such motors have been applied for the direct drive applications. Especially, the rare-earth hard magnetic materials are used in these PM motors to achieve higher and higher performance [4]. However, the supply of rare-earth is exclusive and the cost of such materials is fluctuated and more and more increasing [5]. Therefore, many researches are being conducted for decreasing the dependence on rare-earth PM in electrical machines.

There are some representative candidates for replacing rare-earth PM machines. One of these candidates is the use of alternative motors with ferrite PM [5-8]. Although the ferrite PM has high productivity and cost competitiveness compared with rare-earth PM $[9,10]$, the residual flux density of the motor with ferrite PM is lower than that of the rare-earth PM motor by at least two to three times [11,12]. Another candidate is the motors without PM, such as switched reluctance motor and synchronous reluctance motor (SynREL) [13,14]. Since these motors do not require the PM, they have advantages in terms of price and irreversible demagnetization fault. In contrast with the advantages, they have higher torque ripple and lower torque density than the motor using the PM $[15,16]$. The other candidate is the PM assistant SynREL (PMaREL) [16-19]. In case of the PMaREL, the torque density can be increased, compared with the conventional SynREL. However, the torque ripple of the PMaREL is still higher than that of the PM motor, such as the surface-mounted PM (SPM) or interior PM (IPM) motor.

All candidates have their advantages and disadvantages, but it is difficult to choose which one is the best from these pros and cons. This is because all representative studies 
have been analyzed based on different criteria. Therefore, in order to select which candidate is most suitable for each field to be applied, it is important to compare with the same criteria.

This paper considers some alternative motors to substitute for rare-earth PM motors in direct drive applications. These motors are analyzed and their performance is compared under the one criteria. The focus is on comparing synthetically the characteristics of these representative candidates. Finally, the strengths and weaknesses of such alternative motors are found out through the comparison of their capability to meet specific requirements.

\section{Reference Motor and Alternatives}

\subsection{Reference Motor}

The reference motor used in the direct drive application that is considered hereafter is a SPM motor adopting Neodymium-Iron-Boron (NdFeB) PM. A sketch of its geometry is shown in Figure 1. The motor data are reported in Table 1.

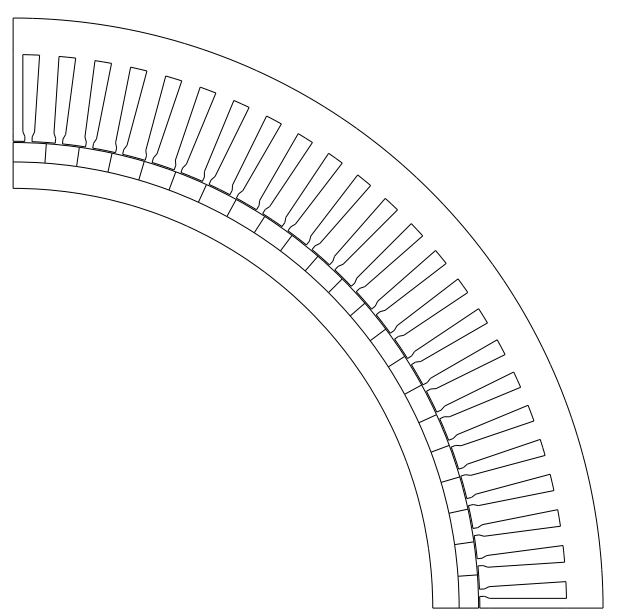

Figure 1. NdFeB SPM motor used as reference motor.

Table 1. Main data of the reference SPM motor.

\begin{tabular}{ccc}
\hline Item & Unit & Reference \\
\hline The number of poles & - & 88 \\
The number of slots & - & 96 \\
Motor type & - & SPM \\
Magnet type & - & NdFeB PM \\
Stator outer diameter & $\mathrm{mm}$ & 485 \\
Stator inner diameter & $\mathrm{mm}$ & 383.7 \\
Rotor outer diameter & $\mathrm{mm}$ & 382.7 \\
Rotor inner diameter & $\mathrm{mm}$ & 345 \\
Airgap length & $\mathrm{mm}$ & 0.5 \\
Stack length & $\mathrm{mm}$ & 80 \\
\hline
\end{tabular}

\subsection{Alternatives}

To the aim of substituting for a rare-earth SPM motor, four alternative motor types are selected. They are shown in Figures 2-5. Excluding the SynREL motor, Ferrite PM is chosen for the PM motors. The specifications of these four motors are summarized in Table 2. The stator diameters and the stack length of alternative motors are same of those of the reference motor. 


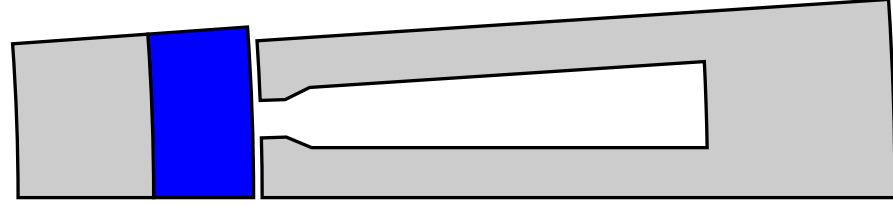

Figure 2. SPM motor with Ferrite PMs (SPM).

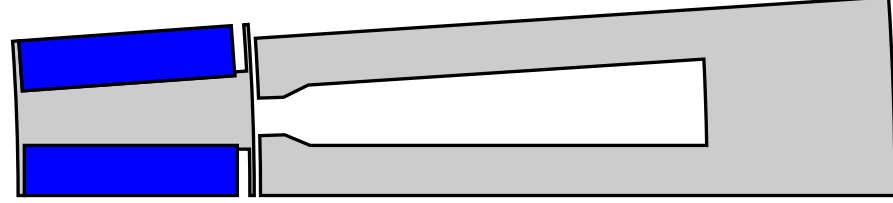

Figure 3. Spoke type motor with Ferrite PMs (Spoke).

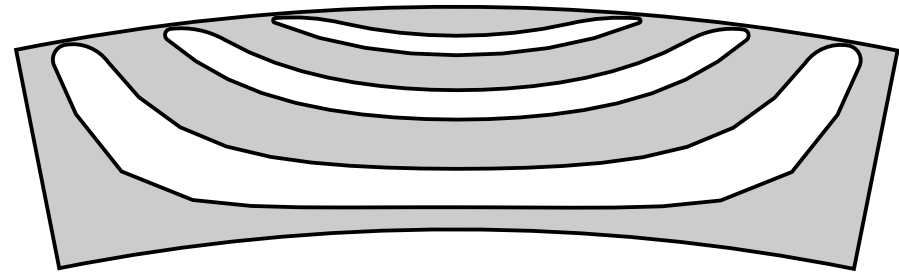

Figure 4. SynREL motor without PM (SynREL).

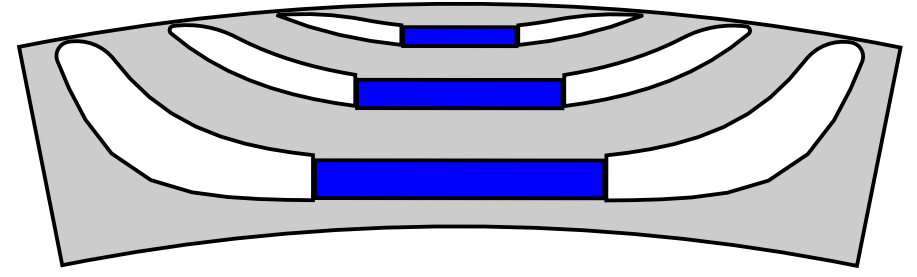

Figure 5. PMaREL motor with Ferrite PMs (PMaREL).

Table 2. Specification of alternatives.

\begin{tabular}{cccccc}
\hline Item & Unit & SPM & Spoke & SynREL & PMaREL \\
\hline The number of poles & - & 88 & 88 & 16 & 16 \\
The number of slots & - & 96 & 96 & 96 & 96 \\
Stator outer diameter & $\mathrm{mm}$ & 485 & 485 & 485 & 485 \\
Stator inner diameter & $\mathrm{mm}$ & 383.7 & 383.7 & 383.7 & 383.7 \\
Rotor outer diameter & $\mathrm{mm}$ & 382.7 & 382.7 & 382.7 & 382.7 \\
Rotor inner diameter & $\mathrm{mm}$ & 345 & 345 & 345 & 345 \\
Airgap length & $\mathrm{mm}$ & 0.5 & 0.5 & 0.5 & 0.5 \\
Stack length & $\mathrm{mm}$ & 80 & 80 & 80 & 80 \\
Magnet type & - & Ferrite & Ferrite & - & Ferrite \\
Magnet volume & $\mathrm{m}^{3}$ & 0.75 & 0.96 & - & 0.17 \\
\hline
\end{tabular}

The first proposal is an SPM motor with Ferrite PMs, shown in Figure 2. This motor only changes the magnet type and the design is the same with the reference motor. The second candidate is a spoke type motor with Ferrite PMs, shown in Figure 3. The motor has the same number of poles and slots, compared with the reference motor. The third alternative is a SynREL without PM, shown in Figure 4. Final suggestion is a PMaREL using Ferrite PMs, shown in Figure 5. The third and fourth motors have 16 poles and 96 slots. The stator size is the same of the reference motor. The volume of Ferrite magnet that is utilized in each motor is different and depends on the rotor geometry. The spoke type motor uses a volume of magnet higher than the other alternative PM motors. 


\section{Comparison of Performance}

Fixing the same size for all motors and the same operating conditions allows a proper analysis and comparison of the performance of all alternative motors. The operating conditions are reported in Table 3.

At first, the characteristics of the reference motor are analyzed. They are shown in Figure 6. The maximum value of the (no-load) flux linkage is $0.71 \mathrm{Vs}$. The average torque is $762 \mathrm{Nm}$ at the rated current, and the torque ripple is $3.8 \%$.

Table 3. Operating condition.

\begin{tabular}{ccc}
\hline Item & Unit & Condition \\
\hline Rated speed & rpm & 40 \\
Rated current & $\mathrm{A}_{r m s}$ & 12.6 \\
Peak current & $\mathrm{A}_{r m s}$ & 37.2 \\
DC bus voltage & $\mathrm{V}_{d c}$ & 600 \\
Maximum temperature & ${ }^{\circ} \mathrm{C}$ & 130 \\
\hline
\end{tabular}

The first alternative exhibits flux linkage and torque as in Figure 7 . The maximum value of the flux linkage is $0.245 \mathrm{Vs}$ under no load condition and the average torque is $274.1 \mathrm{Nm}$, when the rated current is $12.6 \mathrm{~A}_{r m s}$. The torque ripple is $2.55 \%$. These results are not satisfactory for replacing the reference NdFeB SPM motor. This is apparent because the residual flux density of the Ferrite PMs is quite lower than that of the NdFeB PMs by at least two to three times.

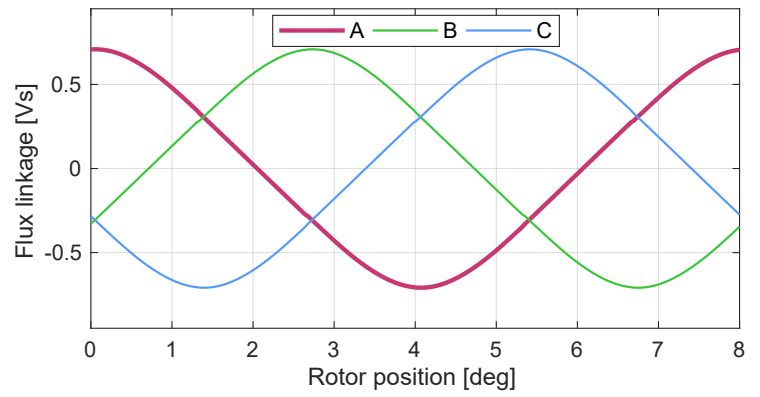

(a)

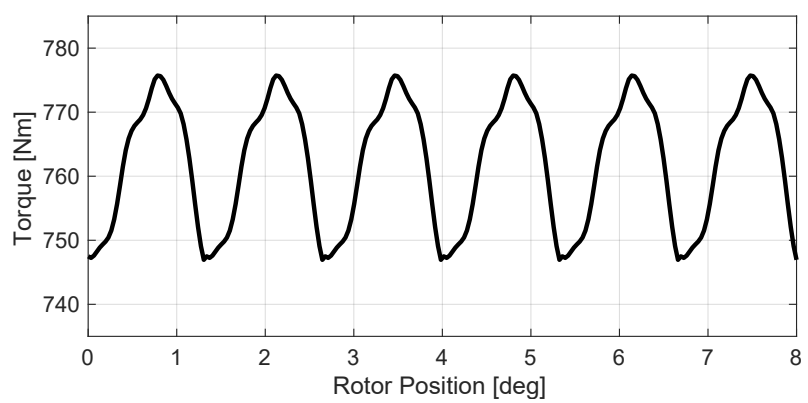

(b)

Figure 6. Analysis of the reference motor. (a) Flux linkage, (b) Torque.

The performance of the second alternative is shown in Figure 8. Under no-load condition, the maximum value of the flux linkage is $0.37 \mathrm{Vs}$ and the average torque is $445 \mathrm{Nm}$. The torque ripple is $6.22 \%$. In the spoke motor the flux results to be concentrated in the air gap, so that higher performance are achieved. The amount of magnet is larger than in the SPM motor. However, as expected, these results are still lower than that of the reference motor. 


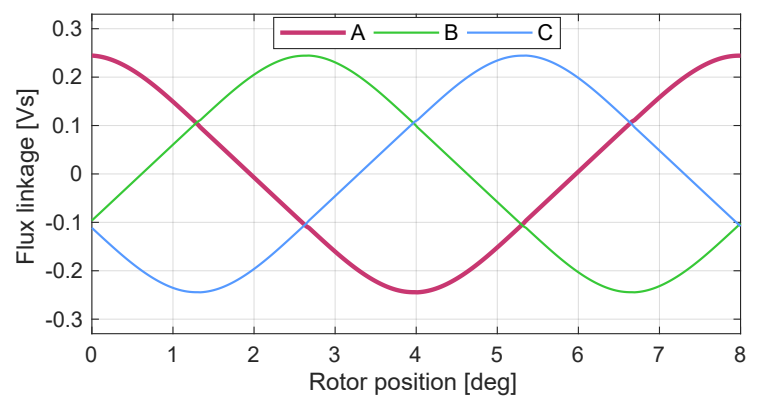

(a)

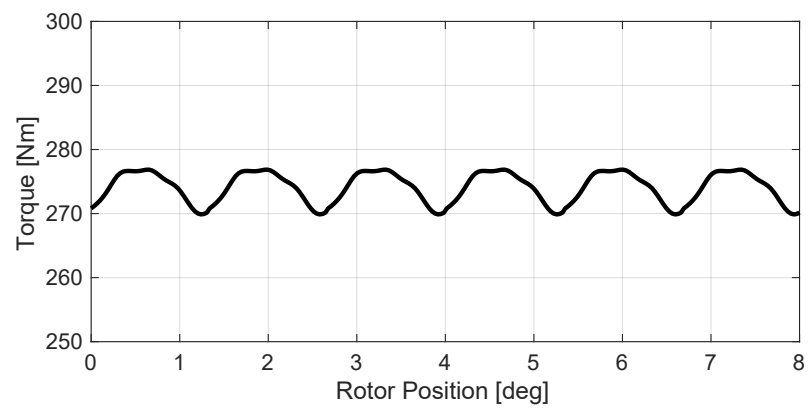

(b)

Figure 7. Analysis of the SPM motor. (a) Flux linkage, (b) Torque.

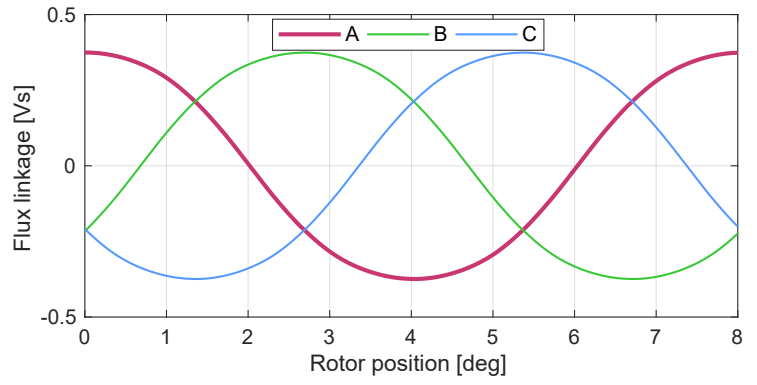

(a)

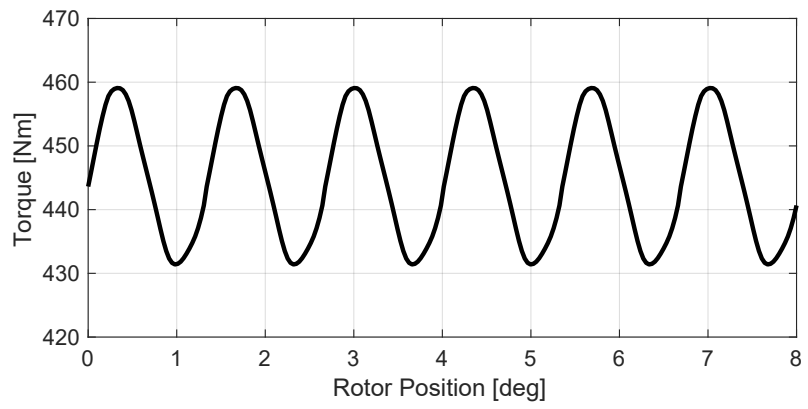

(b)

Figure 8. Analysis of the Spoke motor. (a) Flux linkage, (b) Torque.

In case of the SynREL motor, since there is no magnet in the rotor, there is only reluctance torque. The torque characteristic is shown in Figure 9. When the rated current is $12.6 \mathrm{~A}_{r m s}$, the average torque is $383.2 \mathrm{Nm}$ and the torque ripple is $13.3 \%$. Although the barrier of SynREL motor was already optimized for getting minimimum torque ripple, unlike previous motors, the torque ripple of SynREL motor is more than three times higher than the reference motor.

At last, Figure 10 shows the performance of the PMaREL motor. For improving the performance of SynREL, the PMaREL is developed. The PMaREL uses both of the magnetic 
and reluctance torques. The maximum value of the flux linkage is $0.414 \mathrm{Vs}$ at no-load. The average torque is $426.3 \mathrm{Nm}$, when the rated current is $12.6 \mathrm{~A}_{r m s}$. Even though the volume of magnet is less than SPM and Spoke motors, the torque results to be higher than the SPM motor and similar with the spoke-type motor. However, the torque ripple is $17.5 \%$, which is the highest among all alternatives.

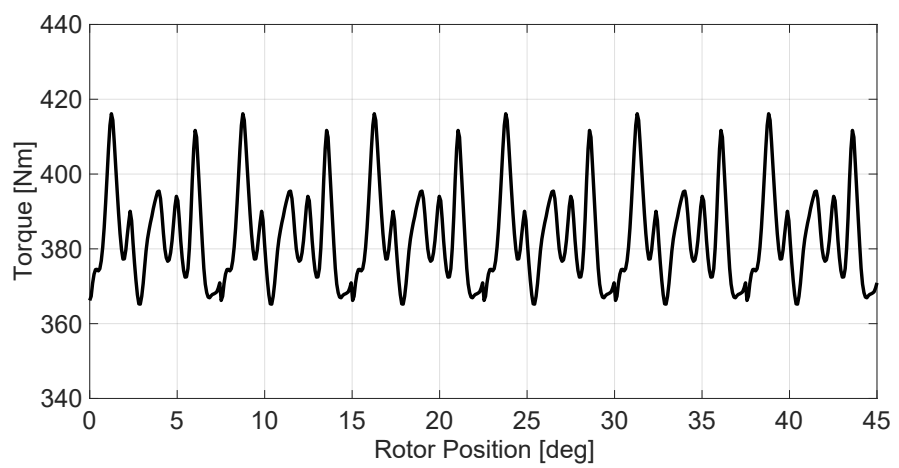

Figure 9. Analysis of the SynREL motor.

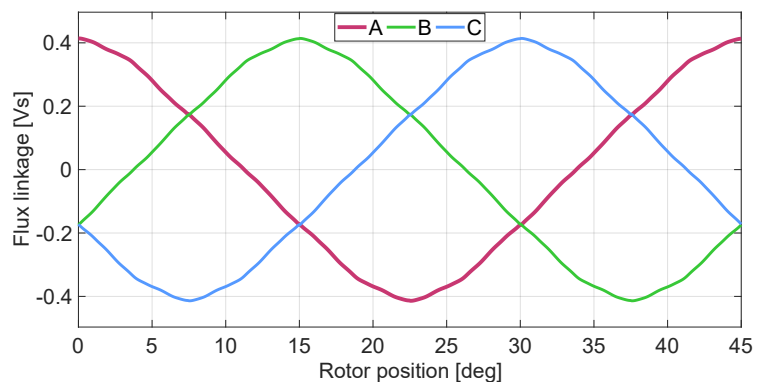

(a)

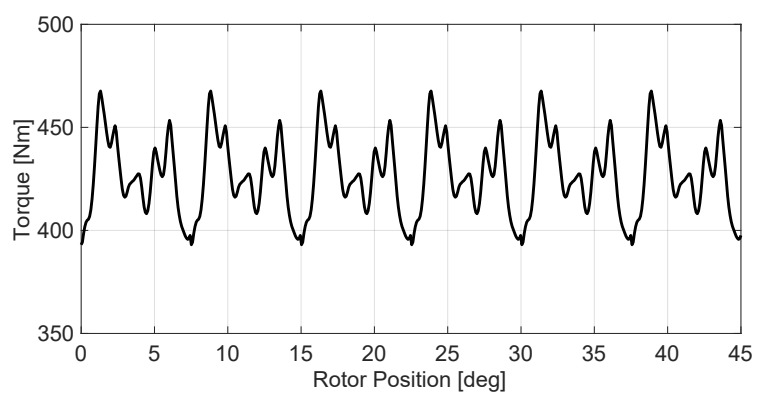

(b)

Figure 10. Analysis of the PMaREL motor. (a) Flux linkage, (b) Torque.

Table 4 reports the performance comparison between the five motors. As expected, with fixed motor size, the average torque of the alternative motors is always lower than that of the reference motor. However, comparing the performance per volume of all alternative motors, it results that the torque of spoke type Ferrite PM motor is higher than other motors, even if its volume of magnet is also higher. In addition, almost all alternative motors exhibit a higher torque ripple. Anyway, through the optimization of the rotor, it is possible to decrease such a torque ripple. 
Table 4. Performance comparison among the five motors.

\begin{tabular}{clccccc}
\hline Item & Unit & Ref & SPM & Spoke & SynREL & PMaREL \\
\hline Volume & p.u. & 1 & 1 & 1 & 1 & 1 \\
Flux linkage & p.u. & 1 & 0.35 & 0.52 & - & 0.58 \\
Torque & p.u. & 1 & 0.36 & 0.58 & 0.5 & 0.56 \\
Torque ripple & p.u. & 1 & 0.67 & 1.64 & 3.5 & 4.6 \\
\hline
\end{tabular}

Note: Here, Ref and p.u. mean the reference motor and per unit, respectively.

In order to improve the performance, the alternative motor size has to be increased so that their average torque matches with the reference motor torque. As a result, for the SPM motor the stack length increases to $220 \mathrm{~mm}$. In case of Spoke motor, the stack length increases to $140 \mathrm{~mm}$. For the SynREL motor the stack length is doubled as the reference motor, reaching a $766.4 \mathrm{Nm}$-torque. The stack length of the PMaREL motor is increased to $145 \mathrm{~mm}$, and the average torque reaches $772 \mathrm{Nm}$.

Figure 11 shows the joule and iron losses of all motors, when the volume of all motors is identical and the speed is increased until $40 \mathrm{r} / \mathrm{min}$. The iron losses of the reference motor are higher because of the high magnetic density of NdFeB PM, while they are lower in the SynREL motor is the lowest due to no magnet. On the contrary, the joule losses are higher in PMaREL and SynREL motors. Since the amount of joule losses is much larger than the iron losses, the total losses of PMaREL motor are dominant.

By considering these losses, the efficiency of all motors is also computed, as shown in Figure 12.

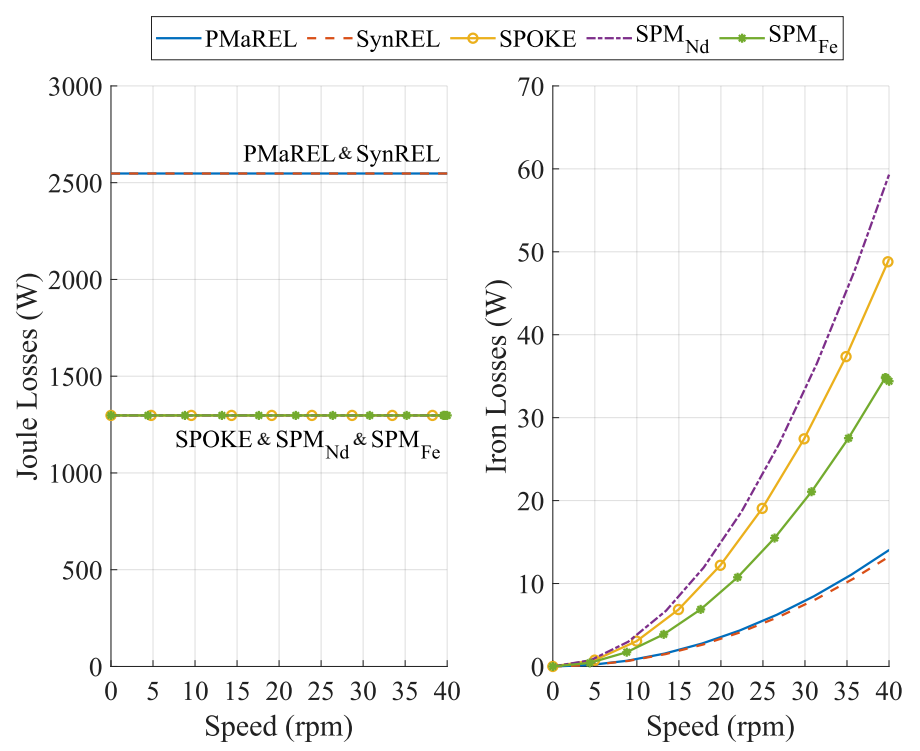

Figure 11. Losses of all motors according to speed. 


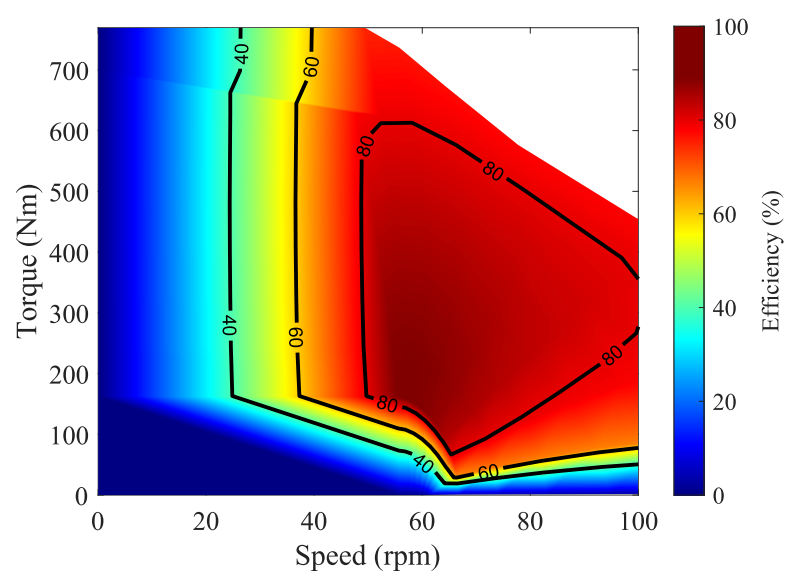

(a)

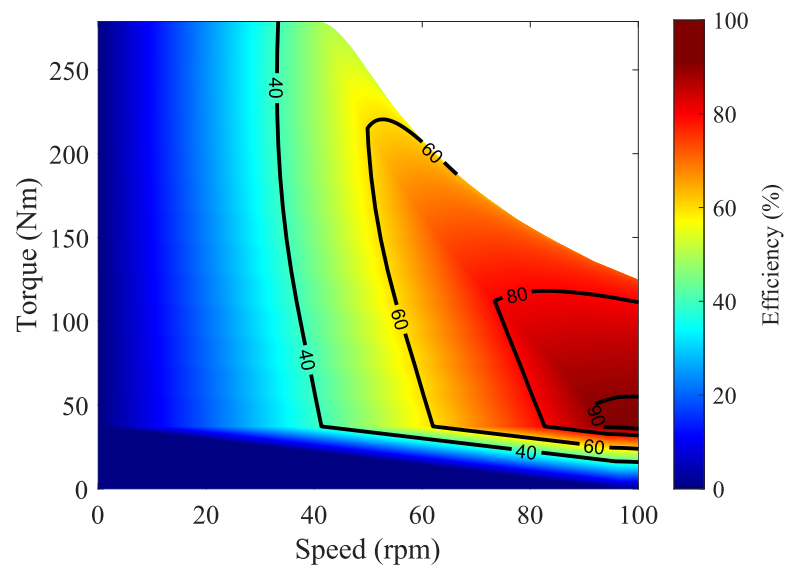

(b)

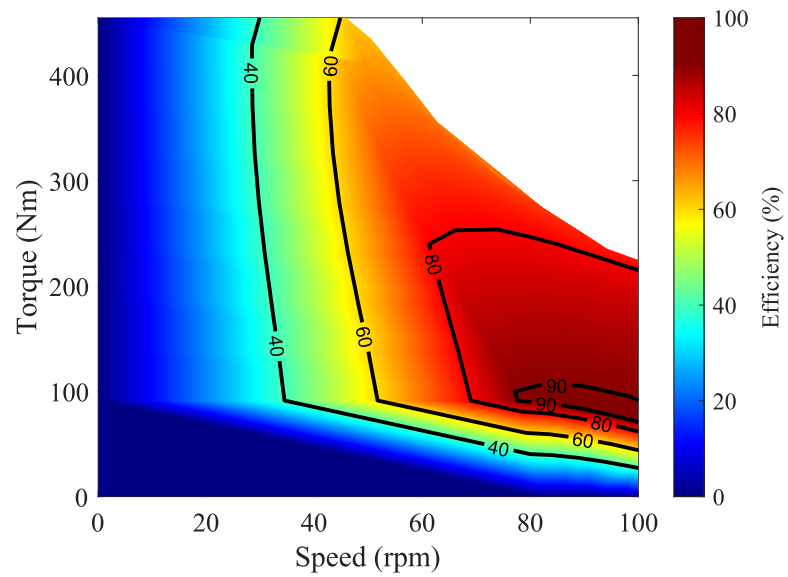

(c)

Figure 12. Cont. 


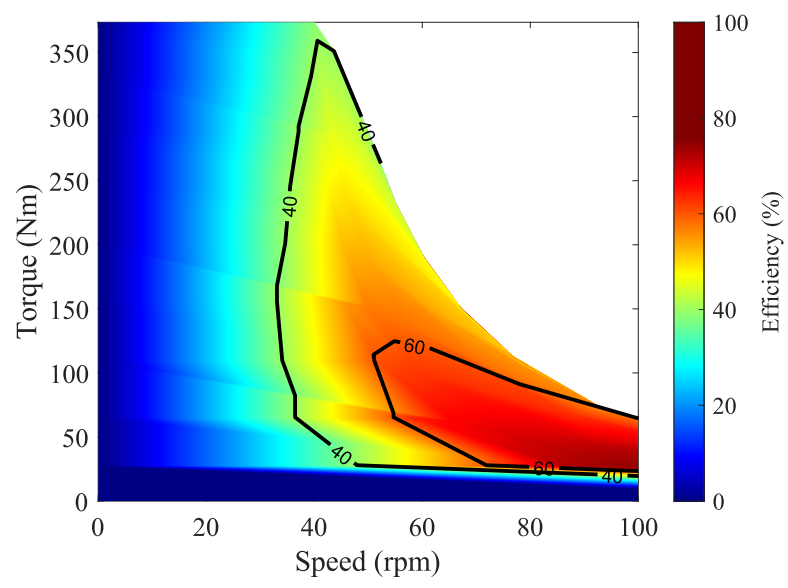

(d)

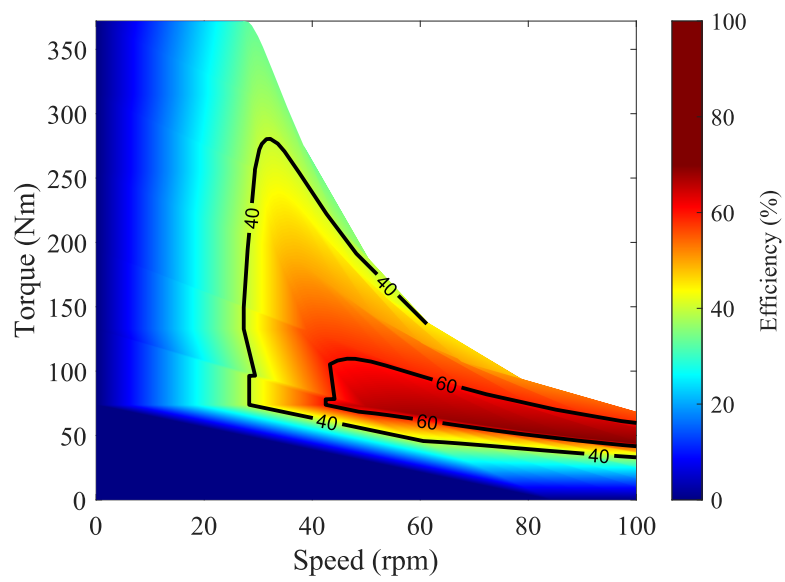

(e)

Figure 12. The efficiency according to speed. (a) Reference motor, (b) SPM motor, (c) Spoke motor, (d) SynREL motor, (e) PMaREL motor.

The maximum efficiency of reference motor is $85 \%$. Compared with the SPM and Spoke motors, the joule losses are the same, but the iron losses are different. In particular, the iron losses of the SPM motor are the lowest. Thus, the maximum efficiency of the SPM and Spoke motors are $91 \%$ and $86 \%$, respectively. Since the joule losses of SynREL and PMaREL motors are higher than that of other types, there is a reduction of the efficiency. It is equal to $74 \%$ and $78 \%$ for the SynREL and PMaREL motor, respectively. Consequently, for replacing the reference motor with $\mathrm{NdFeB} \mathrm{PM}$ in direct drive applications, the Spoke motor results to be well-suited in terms of torque and efficiency.

\section{Demagnetization Analysis}

Adopting PM motors, the capability of the motor is strictly dependent on the magnet property. In this section the motor types are analysed according to the capability to withstand a flux in direction opposite to the magnetization direction.

$\mathrm{NdFeB}$ and Ferrite PMs have an opposite behaviour according to the temperature variation [5], as shown in the B-H characteristic of Figure 13. When the temperature increases, the knee point of B-H curve is changed. In case of NdFeB PM, the knee point is moved from the third quadrant to the second quadrant. As a result, the irreversible demagnetization can occur at high temperature. Unlike the NdFeB PM, although the knee point of the Ferrite PMs is moved toward the third quadrant, the residual flux density is also decreased at high temperature. In particular, due to lower residual flux density and coercive force, the Ferrite PM is easily demagnetized by the reversed flux, compared 
with the NdFeB PM. Thus, it is essential to check the irreversible demagnetization at high current and temperature.

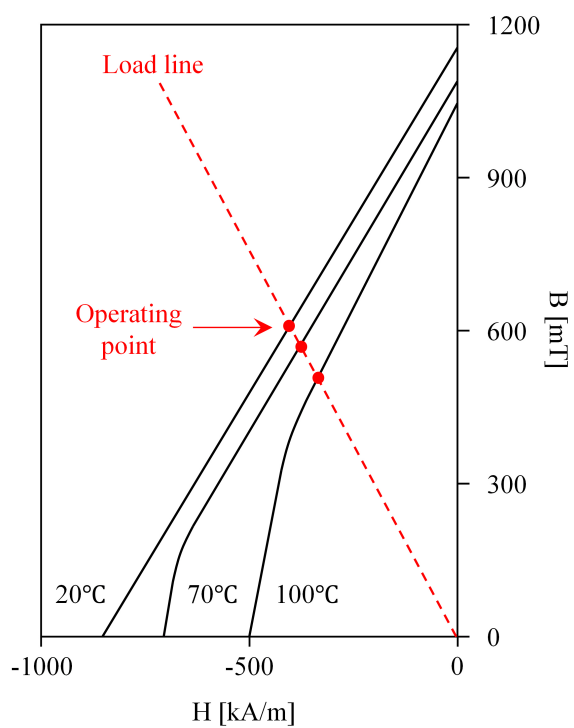

(a) NdFeB PM

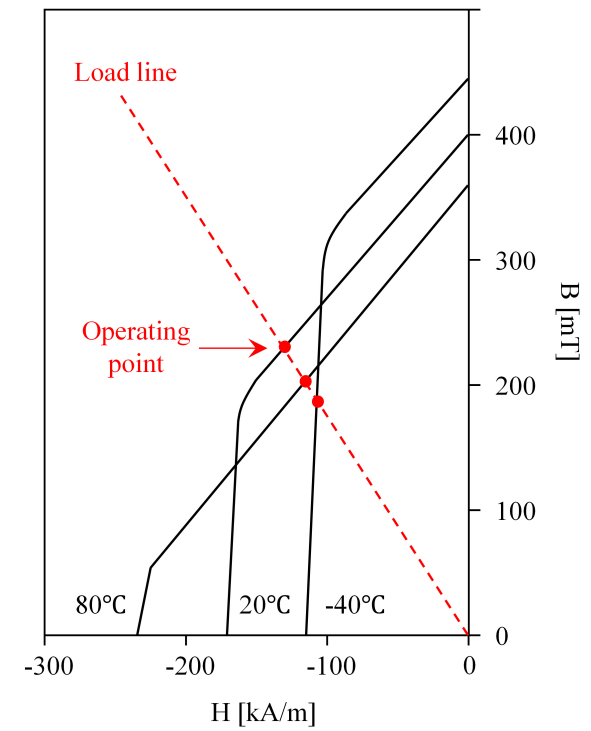

(b) Ferrite PMs

Figure 13. B-H characteristic of NdFeB PM and Ferrite PMs.

To the aim of investigating the demagnetization phenomenon, the flux density of each motor is analyzed according to the load condition. The rated current is fixed to $12.6 \mathrm{~A}_{\mathrm{rms}}$ and the peak current to $37.2 \mathrm{~A}_{r m s}$, (considered for the overload operating conditions, or stall torque), and the temperature is assumed to be $130{ }^{\circ} \mathrm{C}$. Unlike other motors, the peak current of the PMaREL motor is fixed to be $30 \mathrm{~A}_{r m s}$ because the torque of PMaREL consists of the reluctance torque and magnetic torque, and the reluctance torque is much higher than the magnetic torque. Since the reluctance torque is increased by the product of $d$-axis current and $q$-axis current and the magnetic torque increases by only $d$-axis current, in case of PMaREL, the peak current for the stall torque is less than the other cases.

Additionally, particular attention is given to the zone of the magnets that is highly affected by the flux of reversed direction. In case of SPM with NdFeB PM or Ferrite PMs, since the magnets are located on the rotor outer surface, the surface of magnet is affected by the reversed flux. In case of spoke type PM motor, the edge of the magnet is easily demagnetized by the reversed flux. Then, in case of PMaREL motor, the first magnet (buried in the flux-barrier closer to the gap) is mainly focused for analyzing the demagnetization phenomenon. Figures 14-17 show the PM demagnetization of each motor. The flux density of the magnet is observed according to load condition.
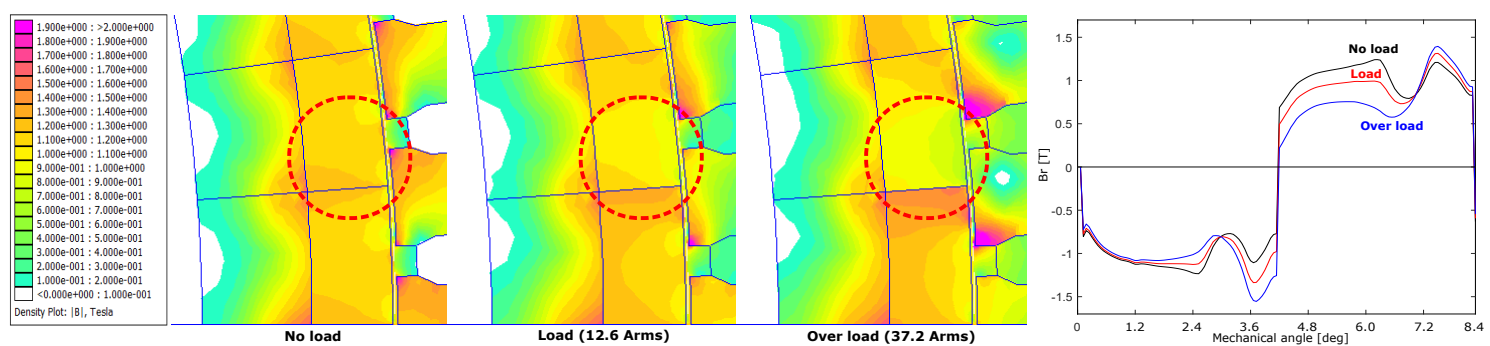

Figure 14. Demagnetization analysis of the reference motor. 

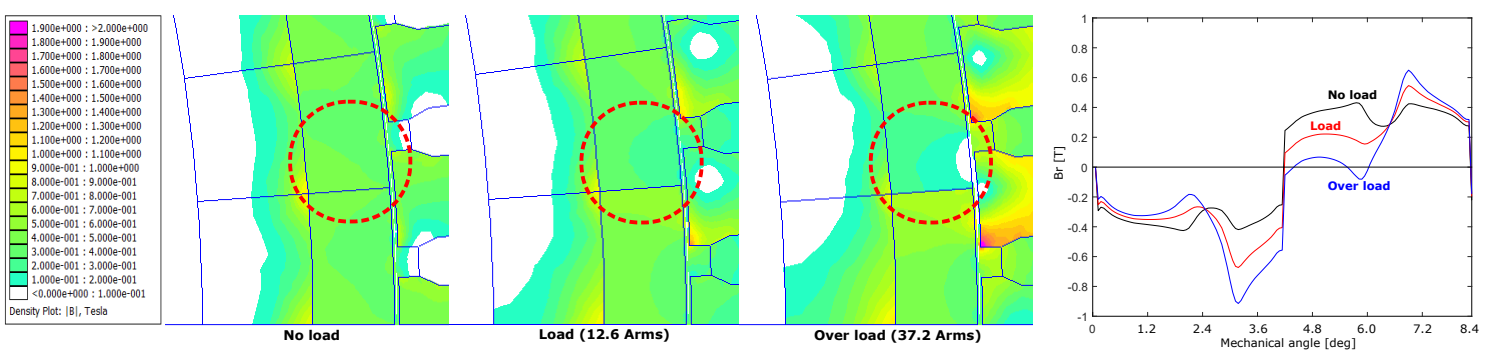

Figure 15. Demagnetization analysis of the Ferrite SPM motor.
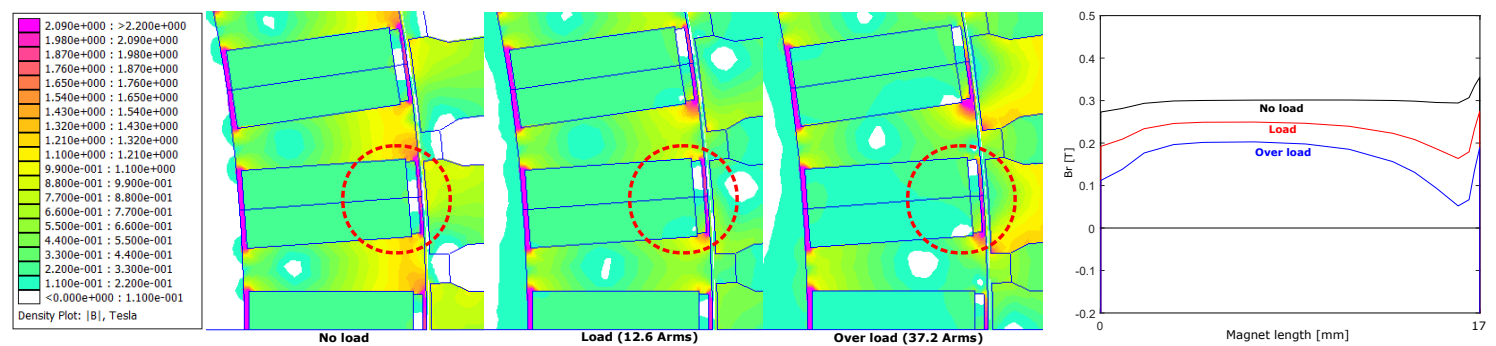

Figure 16. Demagnetization analysis of the Ferrite PM spoke motor.
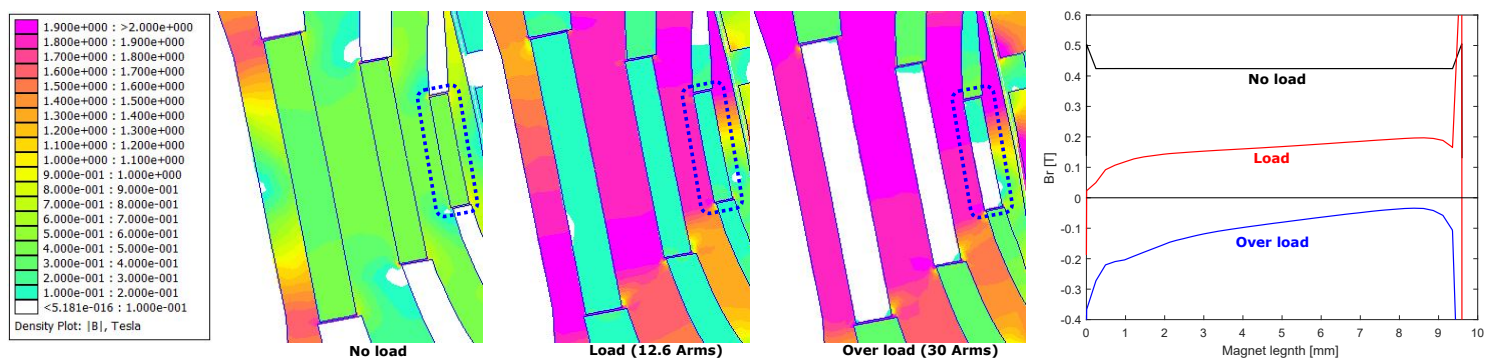

Figure 17. Demagnetization analysis of the Ferrite PMaREL motor.

The reference motor with $\mathrm{NdFeB} \mathrm{PM}$ is affected by increasing the current, but the flux density of the NdFeB PM maintains over the knee point. It means that the magnet works along the reversible recoil line, as shown in Figure 14.

In the Ferrite SPM motor, there is a huge effect of the reversed flux on the magnet. It is evident by comparing it with the motor with NdFeB PM. A wide part of Ferrite magnet is irreversibly demagnetized under overload condition, as evident in Figure 15. As a result, the first alternative is unsuitable for replacing the NdFeB SPM motor utilized in the direct drive applications.

In case of the spoke type motor with Ferrite PMs, the magnet operates properly under nominal load. However, the edge part is affected by the reversed flux under overload condition, as shown in Figure 16. This kind of machine has to be designed carefully to satisfy the overload conditions since the flux density is quite close to the knee of the $\mathrm{BH}$ curve. Although the reversed flux affects the edge part, the most area of magnet withstands the stator reversed flux even in overload condition. Thus, the performance of second motor can be maintained despite of the demagnetization on the edge part.

The magnet of PMaREL motor is thinner than other motors because the rotor area is limited and it is difficult to increase the thickness of the magnets. As a result, when the motor is operated under overload, each magnet results to be irreversibly demagnetized by the reversed flux, as shown in Figure 17. Therefore, the PMaREL with Ferrite PMs results to be unsuitable for subsitituting the reference motor, without a complete re-design of the rotor flux-barriers. 


\section{Result and Discussion}

Finding out the advantages and disadvantages, Table 5 shows the overall comparison between the four candidates and indicates the ranking according to five items: average torque, torque ripple, total losses, efficiency, and capability to withstand the irreversible demagnetization. In this comparison all motors have the same size, equal to the reference motor.

Table 5. The ranking of all alternatives.

\begin{tabular}{ccccc}
\hline Item & SPM & Spoke & SynREL & PMaREL \\
\hline Torque & 4 & 1 & 3 & 2 \\
Torque Ripple & 1 & 2 & 3 & 4 \\
Total loss & 1 & 2 & 3 & 4 \\
Efficiency & 1 & 2 & 4 & 3 \\
Demagnetization & 3 & 2 & 1 & 4 \\
\hline Average & 2 & 1.8 & 2.8 & 3.4 \\
\hline Note: $1,2,3$, and 4 denote the ranking. The lower ranking means better aspect than the higher number.
\end{tabular}

Note: 1, 2, 3, and 4 denote the ranking. The lower ranking means better aspect than the higher number.

According to the ranking, the SPM motor with Ferrite PMs exhibits low torque ripple and high efficiency, but a low ratio between torque and motor volume. In addition, this motor is not suitable to operate with high currents: irreversible demagnetization occurs under high load condition. The spoke type motor with ferrite PMs exhibits a torque per motor volume ratio higher than the other alternatives. Its efficiency is almost similar to that of the reference motor. Morever, it can withstand a high reversed flux. The torque ripple results to be higher than the SPM motors so that it is necessary that the rotor geometry is optimized for reducing the ripple.

The SynREL motor is the cheapest in terms of cost, however, it exhibits a low torque density and a torque ripple higher than other motors, although the barrier positions were optimized for reducing the ripple, according to the required available rotor space. An improvement is reached by introducing Ferrite PMs in the flux-barriers. In fact, the PMaSyRM motor exhibits a torque per volume ratio similar to that of the spoke type motor, but the torque ripple is again higher than the other motors. In addition, an irreversible demagnetization occurs under overload condition when the thickness of the flux-barriers is low. At last, the efficiency of the SynREL and PMaREL motors are quite lower. Finally, the spoke type motor with Ferrite PMs seems to be the proper alternative for replacing the reference motor in the direct drive application.

According to the analysis presented above the spoke-type Ferrite PM motor has been chosen as a small-size prototype. Some measures of torque have carried out, as also reported in Figure 18. The motor has been tested up to a current $30 \%$ higher than the nominal value. It has been verified that the motor exhibits a quite high torque density. However, it results slightly lower than expected from the 2D finite element analysis. This reduction has been imputed to the leakage flux on the two end parts of the rotor. At first this leakage flux depends on the rotor geometry, and can be considered to be a constant quantity on both the lateral parts of the rotor. Thus, its relative amount varies with the stack length of the motor.

As far as the torque ripple is concerned, it remains quite low, as predicted by means of the electromagnetic analysis. As a result, the motor performance remains the same even after the overload operations. This means that the PMs were not affected by ireversible demagnetization. A further verification was carried out on the electromagnetic force induced by the PMs. The motor was tested several time and it reproduced the same torques for given currents. 


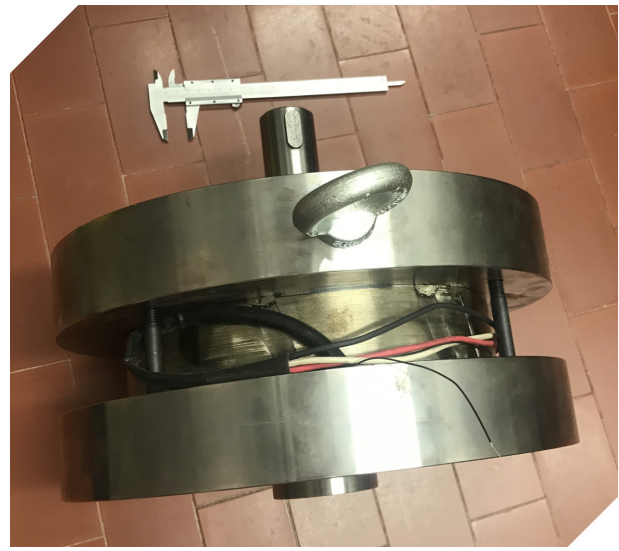

(a) Motor prototype

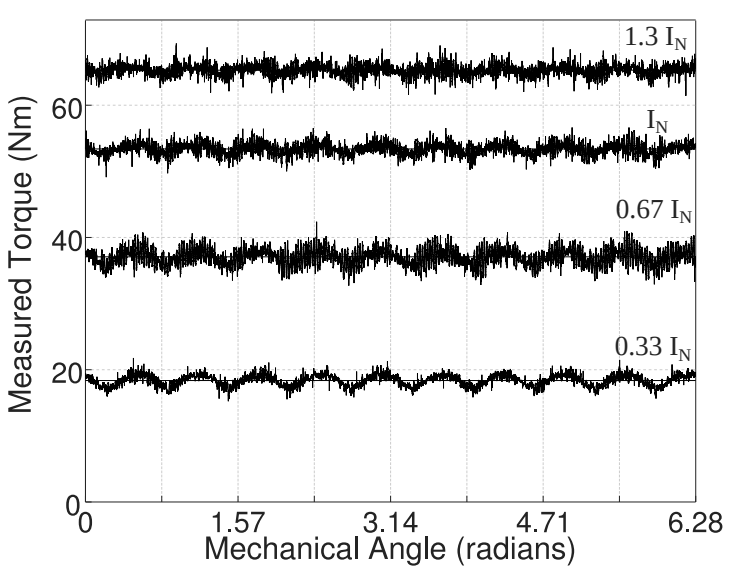

(b) Torque measured on a motor prototype

Figure 18. Experimental results.

\section{Conclusions}

This paper considers some alternatives to the NdFeB SPM motor for direct drive applications. Based on previous studies, the analysed motor types which are chosen as possible candidates are the Ferrite SPM and Spoke motors, the SynREL and the PMaREL motors. Considering the cost issue, the ferrite magnet was selected for replacing the NdFeB PM. The characteristics of representative candidates were compared with the reference motor. Since the results were presented through the ranking, the advantages and disadvantages of each alternative were clearly highlighted. As a result, the Spoke motor had the lowest ranking point among all candidates, making it the most suitable type to replace the NdFeB SPM motor.

Although the Spoke motor is the best through the ranking, the torque ripple still remains. Thus, the problem must be solved by using an optimization process after selection. Additionally, this result can be only applied to the direct drive applications. If a proper alternative in other applications has to be found, after all candidates are analyzed, a new ranking should be made repeatly.

Author Contributions: Conceptualization, C.J. and N.B.; methodology, C.J. and N.B.; software, C.J. and L.C.; validation, C.J., L.C. and N.B.; investigation, C.J. and N.B.; writing-original draft preparation, C.J.; writing-review and editing, C.J. and N.B.; supervision, N.B.; All authors have read and agreed to the published version of the manuscript.

Funding: This research received no external funding.

Institutional Review Board Statement: Not applicable.

Informed Consent Statement: Not applicable.

Acknowledgments: This work was supported by the Tongmyoung University Research Grants 2021A007.

Conflicts of Interest: The authors declare no conflict of interest.

\section{References}

1. Jeong, C.; Park, J.; Bianchi, N. Alternatives to replace rare-earth permanent magnet motors in direct drive applications. In Proceedings of the International Symposium on Power Electronics, Electrical Drives, Automation and Motion, Sorrento, Italy, 24-26 June 2020.

2. Onsal, M.; Cumhur, B.; Demir, Y.; Yolacan, E.; Aydin, M. Rotor design optimization of a new flux-assisted consequent pole spoke-type permanent magnet torque motor for low-speed applications. IEEE Trans. Magn. 2018, 54, 8206005.

3. Zhang, Z.; Zhao, Y.; Qiao, W.; Qu, L. A space-vector-modulated sensorless direct-torque control for direct-drive pmsg wind turbines. IEEE Trans. Ind. Appl. 2014, 50, 2331-2341. [CrossRef] 
4. Zhang, Y.; Cao, W.; McLoone, S.; Morrow, J. Design and flux-weakening control of an interior permanent magnet synchronous motor for electric vehicles. IEEE Trans. Appl. Super. 2016, 26, 1-6.

5. Barcaro, M.; Bianchi, N. Interior PM machines using ferrite to replace rare-earth surface PM machines. IEEE Trans. Ind. Appl. 2014, 50, 979-985. [CrossRef]

6. Rahman, M.M.; Kim, K.T.; Hur, J. Design and optimization of neodymium-free spoke-type motor with segmented wing-shaped pm. IEEE Trans. Magn. 2014, 50, 865-868. [CrossRef]

7. Du, Z.; Lipo, T. Design of an improved dual-stator ferrite magnet vernier machine to replace an industrial rara-earth IPM machine. IEEE Trans. Energy Convers. 2019, 34, 2062-2069. [CrossRef]

8. Tahanian, H.; Aliahmadi, M.; Faiz, J. Ferrite permanent magnets in electrical machines: Opportunities and challenges of a non-rare-earth alternative. IEEE Trans. Magn. 2020, 56, 1-20. [CrossRef]

9. Tariq, A.R.; Nino-Baron, C.E.; Stranges, E.G. Consideration of magnet materials in the design of pmsms for hevs application. In Proceedings of the 2011 IEEE Power and Energy Society General Meeting, Detroit, MI, USA, 24-28 July 2011.

10. Petrov, I.; Pyrhonen, J. Performance of low-cost permanent magnet material in pm synchronous machines. IEEE Trans. Ind. Electron. 2013, 60, 2131-2138. [CrossRef]

11. Dorrell, D.G.; Hsieh, M.; Popescu, M.; Evans, L.; Staton, D.A.; Grout, V. A review of the design issues and techniques for radial-flux brushless surface and internal rare-earth permanent-magnet motors. IEEE Trans. Ind. Electron. 2011, 58, 3741-3757. [CrossRef]

12. Widmer, J.D.; Martin, R.; Kimiabeigi, M. Electric vehicle traction motors without rare earth magnets. Sustain. Mater. Technol. 2015, 3, 7-13. [CrossRef]

13. Zhu, Z.Q.; Liu, X. Novel stator electrically field excited synchronous machines without rare-earth magnet. In Proceedings of the 2014 Ninth International Conference on Ecological Vehicles and Renewable Energies (EVER), Monte-Carlo, Monaco, 25-27 March 2014.

14. Chiba, A.; Kiyota, K.; Hoshi, N.; Takemoto, M.; Ogasawara, S. Development of a rare-earth-free sr motor with high torque density for hybrid vehicles. IEEE Trans. Energy Convers. 2015, 30, 175-182. [CrossRef]

15. Chiba, A.; Takano, Y.; Takeno, M.; Imakawa, T.; Hoshi, N.; Takemoto, M.; Ogasawara, S. Torque density and efficiency improvements of a switched reluctance motor without rare-earth material for hybrid vehicles. IEEE Trans. Ind. Appl. 2011, 47, 1240-1246. [CrossRef]

16. Bianchi, N.; Bolognani, S.; Bon, D.; Pre, M.D. Rotor flux-barrier design for torque ripple reduction in synchronous reluctance and pm-assisted synchronous reluctance motors. IEEE Trans. Ind. Appl. 2009, 45, 921-928. [CrossRef]

17. Bonthu, S.S.R.; Arafat, A.K.M.; Choi, S. Comparisons of rare-earth and rare-earth-free external rotor permanent magnet assisted synchronous reluctance motors. IEEE Trans. Ind. Electron. 2017, 64, 9729-9738. [CrossRef]

18. Obata, M.; Morimoto, S.; Sanada, M.; Inoue, Y. Performance of pmarel with ferrite magnets for ev/hev applications considering productivity. IEEE Trans. Ind. Appl. 2014, 50, 2427-2435. [CrossRef]

19. Cai, H.; Guan, B.; Xu, L. Low-cost ferrite pm-assisted synchronous reluctance machine for electric vehicles. IEEE Trans. Ind. Electron. 2014, 61, 5741-5748. [CrossRef] 